Coeliac disease

\section{Gliadin peptide specific intestinal T cells in coeliac disease}

\section{K E A Lundin, L M Sollid}

\section{Can modification of wheat gliadin peptides be used for immunotherapy in coeliac disease?}

$\mathrm{D}$ espite its heterogeneous clinical appearance, coeliac disease has a remarkable uniform human leucocyte antigen (HLA) association. The majority of coeliac disease patients carry a certain variant of HLA-DQ2, the rest carry HLA-DQ8. ${ }^{12}$ As the physiological role of the HLA system is to present peptide fragments of antigens to $\mathrm{T}$ cells, it would seem logical that the HLA-DQ2 and HLA-DQ8 molecules predispose to coeliac disease by presenting peptides to $\mathrm{T}$ cells in the intestinal mucosa. The peptides these $\mathrm{T}$ cells recognise could derive form gluten peptides as coeliac disease is precipitated by intestinal exposure to wheat gluten and related proteins of other cereals. In fact, this simple concept has gained substantial experimental evidence in recent years. ${ }^{12}$ A paper in this issue of $G u t^{3}$ adds further credence to this model [see page 212].

The small intestinal lesion is characterised by inflammation and infiltration of $\mathrm{T}$ cells both in the lamina propria and epithelium. Intraepithelial $\mathrm{T}$ cells are typical of coeliac disease but their significance is uncertain and they are unlikely to recognise gluten presented by HLADQ2. They may represent an innate ("primitive") immune response to gluten. Their lamina propria counterparts however are much more likely to be key players. In the lamina propria, we find $\mathrm{CD}^{+} \mathrm{T}$ cells and dendritic cell type of antigen presenting cells expressing HLADQ2. Therefore, when we first isolated gluten reactive $\mathrm{T}$ cells some 10 years ago from the small intestinal mucosa of coeliac disease patients, some of us hoped that an immediate solution to several conceptual problems was at hand. ${ }^{4}$ It turned out to be a bit more complex.

Following years of work from a small handful of devoted laboratories, we understand several details with respect to these T cells and what they recognise. We know of several of the peptide epitopes involved in the disease. T cell recognition of many, but not all, is dependent on the action of the small intestinal enzyme tissue transglutaminase which converts glutamine residues in gluten to glutamic acid. ${ }^{12}$
It is in this field that the research group of Professor Ciclitira at St Thomas' Hospital has spent some years of work. It is therefore reassuring that they now report results that are in keeping with previous observations. ${ }^{3}$ Four adult coeliac disease patients were examined and small intestinal biopsies were challenged ex vivo with gluten. Thereafter, a cell suspension was made and $\mathrm{T}$ cells expanded. After some weeks of cell culture work they obtained enough $\mathrm{T}$ cells to perform functional testing. It can be read from the paper that this job was not easy and that several obstacles were encountered. They established both polyclonal and monoclonal $\mathrm{T}$ cell lines and found that in most cases $\mathrm{T}$ cells were reactive to an already characterised epitope of an $\alpha$-gliadin with which the intestinal $\mathrm{T}$ cells of most adult coeliac disease patients are reactive. ${ }^{5}$ The present data thus fit nicely with these previous observations.

No new epitopes are characterised in this paper. However, Ellis et al extend the focus of the investigations to a field that may be unknown to some readers of Gut - that is, the field of "the altered peptide ligands". As stated previously, T cells recognise a peptide in the cleft of the HLA molecules. If certain amino acids in the peptide are changed, the result might be that the peptide cannot bind to the HLA molecule and therefore gives no stimulation. Another situation exists if an amino acid that points to the $\mathrm{T}$ cell is changed. In this case the $\mathrm{T}$ cell might still respond, or it may not respond at all, or it might respond qualitatively different. Such different responses can involve skewing of the cytokine secretion of $\mathrm{T}$ cells, induction of longstanding anergy (they will not respond to subsequent antigen challenge), or suppression of bystanders ( $\mathrm{T}$ cells recognising other parts of the same antigen). The phenomenon is well described in rodents. ${ }^{6}$ Unfortunately, the situation is more complex when applied to human autoimmune disease and to this end the results have been unimpressive. ${ }^{7}$ The results presented by Ellis et al demonstrate that substituting amino acids within the core region of a T cell epitope often impairs $\mathrm{T}$ cell recognition, as expected. Although no convincing data are presented as to whether altered gluten peptide ligands can induce qualitatively different $\mathrm{T}$ cell responses (for example, $\mathrm{T}$ cell anergy or bystander suppression), this remains a possibility that ultimately may be extended to therapy. The fact that there exists multiple gluten T cell epitopes in coeliac disease ${ }^{1}$ and that the $\mathrm{T}$ cell receptor usage by gluten specific T cells is diverse ${ }^{4}$ however makes this approach less attractive.

Other more promising alternatives for new treatment modalities include inhibition of $\mathrm{T}$ cell activation by compounds that block peptide binding to HLA-DQ2, inhibitors of tissue transglutaminase that prevent gluten deamidation, and peroral peptidase supplementation that aids complete digestion of immunostimulatory peptides. ${ }^{18}$ At any rate, much work remains before we know whether any of these treatment modalities represent real treatment alternatives to the currently safe, but cumbersome, gluten free diet.

Gut 2003;52:162

\section{Authors' affiliations}

K E A Lundin, Department of Medicine and Institute of Immunology, Rikshospitalet University Hospital, Oslo, Norway

L M Sollid, Institute of Immunology,

Rikshospitalet University Hospital, Oslo, Norway

Correspondence to: Dr K E A Lundin, Department of Medicine, Rikshospitalet University Hospital, N-0027 Oslo, Norway; knut.lundin@rikshospitalet.no

\section{REFERENCES}

1 Sollid LM. Coeliac disease: dissecting a complex inflammatory disorder. Nat Rev Immunol 2002; 2:647-55.

2 Papadopoulos GK, Wijmenga C, Koning F. Interplay between genetics and environment in the development of celiac disease: perspectives for a healthy life. J Clin Invest 2001:108:1261-6.

3 Ellis HJ, Pollock EL, Engel W, et al. Investigation of the putative immunodominant T cell epitopes in coeliac disease. Gut 2002:52:212-7.

4 Lundin KEA, Scott $\mathrm{H}$, Hansen $\mathrm{T}$, et al. Gliadin specific, $\left.\operatorname{HLA}-\mathrm{DQ}(\alpha){ }^{*} 0501, \beta 1{ }^{*} 0201\right)$ restricted $T$ cells isolated from the small intestinal mucosa of celiac disease patients. $J$ Exp Med 1993;178:187-96.

5 Arentz-Hansen H, Körner R, Molberg $\varnothing$, et al. The intestinal $T$ cell response in adult coeliac disease to $\alpha$-gliadin is focused on a single deamidated glutamine targeted by tissue transglutaminase. J Exp Med 2000;191:603-12.

6 Sloan-Lancaster J, Allen PM. Altered peptide ligand-induced partial T cell activation: Molecular mechanisms and role in T cell biology. Ann Rev Immunol 1996;14:1-27.

7 Bielekova B, Martin R. Antigen-specific immunomodulation via altered peptide ligands. J Mol Med 2001;79:552-65.

8 Shan L, Molberg $\varnothing$, Parrot I, et al. Structural basis for gluten intolerance in celiac sprue. Science 2002;297:2275-9. 


\section{Gastrointestinal intraepithelial lymphocytes and T cell lymphomas}

\section{N Farstad, K E A Lundin}

Enteropathy-type intestinal T cell lymphoma is assumed to derive from intraepithelial lymphocytes and recent reports describing an intermediate or "cryptic" stage of this lymphoma in patients with many characteristics of coeliac disease have challenged aspects of our understanding of coeliac disease and lymphoma development

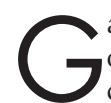
astrointestinal $\mathrm{T}$ cell lymphomas occur less often than those of B cells but have a much more unfavourable prognosis.' Enteropathyassociated T cell lymphoma (EATL) is the predominant subtype, " "enteropathy" indicating a link to coeliac disease (CD). More recently, enteropathy-type intestinal T cell lymphoma (EITCL) seems to be the preferred term for this entity. ${ }^{2}$ EITCL is assumed to derive from intraepithelial lymphocytes (IELs) and recent reports describing an intermediate or "cryptic" stage of this lymphoma in patients with many characteristics of CD have provided a "missing link" in our understanding of the pathogenesis of EITCL. ${ }^{45}$

Refractory coeliac sprue (RCS) is diagnosed in patients with CD-like enteropathy who do not respond to a gluten free diet, primarily or some time after an initial response. ${ }^{6}$ RCS patients with phenotypically normal and polyclonal IELs may respond to immunosuppressive therapy. ${ }^{5}$ However, a large fraction of RCS patients have heavily increased IEL numbers lacking surface CD3 (cytoplasmic $\epsilon$ chains being present) and usually also CD8, in addition to being monoclonal. ${ }^{56}$ Loss of normal $\mathrm{T}$ cell antigens is a common feature of peripheral $\mathrm{T}$ cell lymphomas and these latter patients, despite having no morphologically identifiable tumour, are now diagnosed as having cryptic EITCL. ${ }^{5}$ Not all such cases have ulcerative jejunitis or develop overt lymphoma but most respond poorly to immunosuppression and face a poor prognosis due to severe malabsorption. $^{56}$

Many ordinary CD patients have elevated numbers of IELs in their gastric and/or colonic mucosae. ${ }^{7}$ In the colon, these observations may be explained in part by the known effects of local gluten challenge in the rectum ${ }^{7}$ but less is understood about the pathogenesis of the IEL increase in the gastric mucosa of coeliacs. Interestingly, phenotypically abnormal or monoclonal IELs have been found in the colon of some refractory sprue patients. ${ }^{2}{ }^{8}$ In this issue of Gut, Verkarre and colleagues ${ }^{3}$ confirm that such findings were not incidental [see page 205]. They report from a relatively large series of well characterised RCS patients $(n=15)$ that most $(>60 \%)$ not only have elevated IEL numbers in their gastric and/or colonic mucosae but also that these IELs share the phenotypic and genetic aberrations found in duodenal and jejunal IELs. ${ }^{3}$ Half of the RCS (44\%) patients who had blood samples drawn also showed evidence of dissemination to the circulation because their peripheral blood contained lymphocytes without surface CD3 and CD8 and with identical genetic aberrations to the intestinal IEL counterparts. ${ }^{3}$ Non-refractory coeliacs also often had increased gastric and particularly colonic IELs but these cells were phenotypically and genetically normal except in three samples that were monoclonal. This latter result might be a false positive because those samples contained few and phenotypically normal IELs.

Importantly, Verkarre et al found that 10 RCS patients with neoplastic IELs in the duodenum who also underwent enteroscopy always had the same neoplastic population in the jejunum. ${ }^{3}$ This finding indicates that duodenal biopsy sampling is sufficient to establish a diagnosis of cryptic EITCL, provided adequate laboratory facilities are available. Their data furthermore suggest that a single clone of abnormal $\mathrm{T}$ cells is disseminated throughout the gastrointestinal tract in most RCS patients. This finding challenges several aspects of our understanding of CD and lymphoma development. Firstly, as also discussed by the authors, the large majority of $\mathrm{CD}$ lymphoma cases described were of the EITCL-type and located in the small intestine. One might speculate that the large size of this organ compared with the gastric and colonic mucosa enhances the likelihood that further genetic aberrations leading to overt lymphoma development occur. Secondly, what mechanisms lie behind the observations that colonic and gastric IELs both increase in number and exhibit neoplastic features in RCS? Even in CD, the pathogenesis of the IEL increase is still under debate: do they result from an indirect effect of gluten on the epithelium that in turn releases growth factors for IELs or do they represent a net influx of activated $\mathrm{T}$ cells from the lamina propria into the epithelium? Interestingly, data presented as an abstract ${ }^{9}$ indicate that interleukin 15 (IL-15) is a major growth and survival factor, especially for the abnormal IELs of RCS patients, in addition to being important for local expansion of $\mathrm{T}$ cell receptor (TCR) $\gamma \delta^{+}$ IELs in ordinary coeliacs. ${ }^{9}$ Small intestinal epithelial cells may be the source of IL- 15 in these patients ${ }^{9}{ }^{10}$ but both in the study of Maiuri and colleagues ${ }^{10}$ and in a study on inflammatory bowel disease, IL-15 was especially prominent in subepithelial macrophages and was not found in colonic epithelium. ${ }^{11}$ Even if gluten induces IL-15 in small intestinal epithelial cells or subepithelial macrophages in patients with ordinary CD, what induces IL-15 in the absence of gluten ingestion? Because some CD patients who have been well on a gluten free diet may suddenly present with overt EITCL, it is crucial to reveal the factors responsible for uncontrolled IEL proliferation. The group of RCS patients with normal IELs who often ${ }^{5}$ but not always (Lundin and Farstad, unpublished data) respond to immunosuppression should not be forgotten either; are they at risk of developing cryptic or overt EITCL or do they represent a separate entity?

Lastly, it cannot be excluded that the neoplastic IELs in cryptic EITCL, as supported by the identification of similar clones in peripheral blood of some RCS patients, recirculate between the small intestinal epithelium and other organs such as the gastric or colonic mucosae, skin, liver, and mesenteric lymph nodes. ${ }^{3}$ Specific adhesion and chemokine receptor molecules potentially involved in homing of neoplastic IELs to all of these sites remain to be clarified. At present, small intestinal IELs seem to be characterised mainly by their expression of $\alpha E \beta 7$ integrin and chemokine receptor 9 (CCR9) but TECK/CCL25, the ligand for CCR9, is hardly expressed outside the thymus and small intestine. ${ }^{12}$ In conclusion, it seems difficult to explain the observed dissemination of neoplastic small intestinal IELs in the light of available data. Continued research is needed to understand the pathogenesis and biological implications of this finding.

Gut 2003;52:163-164 


\section{Authors' affiliations}

I N Farstad, Institute of Pathology, University of Oslo, Rikshospitalet, Oslo, Norway

K E A Lundin, Department of Medicine,

University of Oslo, Rikshospitalet, Oslo, Norway

Correspondence to: Dr I N Farstad, Institute of Pathology, Rikshospitalet, N-0027 Oslo,

Norway; i.n.farstad@labmed.vio.no

\section{REFERENCES}

1 Isaacson PG. Gastrointestinal Lymphomas of T- and B-cell types. Mod Pathol 1999; 12:151-8

2 Daum S, Weiss D, Hummel M, et al. Frequency of clonal intraepithelial T lymphocyte proliferations in enteropathy-type intestinal T cell lymphoma, coeliac disease, and refractory sprue. Gut 2001;49:804-12. 3 Verkarre V, Asnafi V, Lecomte T, et al. Refractory coeliac sprue is a diffuse gastrointestinal disease. Gut 2003;52:205-11.

4 Carbonnel F, Grollet-Bioul L, Brouet J, et al. Are complicated forms of celiac disease cryptic T-cell lymphomas? Blood 1998;92:3879-86.

5 Cellier C, Delabesse E, Helmer C, et al. Refractory sprue, coeliac disease, and enteropathy-associated T-cell lymphoma. Lancet 2000;356:203-8.

6 Ryan BM, Kelleher D. Refractory celiac disease. Gastroenterology 2000;1 19:24351

7 Trier JS. Celiac sprue. N Engl J Med 1991;325:1708-19.
8 Fine KD, Lee EL, Meyer RL. Colonic histopathology in untrated celiac sprue or refractory sprue: is it lymphocytic colitis or colonic lymphocytosis? Hum Pathol 1998;29:1433-40.

9 Cerf-Bensussan N, Mention J, Ben Ahmed $M$, et al. 11th International Congress of Mucosal Immunology, Orlando, June 16-20, 2002. Abstract No 1261 .

10 Maiuri L, Ciacci C, Auricchio S, et al. Interleukin 15 mediates epithelial changes in celiac disease. Gastroenterology 2000;1 19:996-1006.

11 Liu Z, Geboes K, Colpaert S, et al. IL-15 is highly expressed in inflammatory bowel disease and regulates local T cell-dependent cytokine production. J Immunol cytokine production.

12 Kunkel EJ, Butcher EC. Chemokines and the tissue-specific migration of lymphocytes. Immunity 2002;16:1-4. 